\title{
Prions, prionoids and protein misfolding disorders
}

Scheckel, Claudia ; Aguzzi, Adriano

\begin{abstract}
Prion diseases are progressive, incurable and fatal neurodegenerative conditions. The term 'prion' was first nominated to express the revolutionary concept that a protein could be infectious. We now know that prions consist of PrPSc, the pathological aggregated form of the cellular prion protein PrPC. Over the years, the term has been semantically broadened to describe aggregates irrespective of their infectivity, and the prion concept is now being applied, perhaps overenthusiastically, to all neurodegenerative diseases that involve protein aggregation. Indeed, recent studies suggest that prion diseases (PrDs) and protein misfolding disorders (PMDs) share some common disease mechanisms, which could have implications for potential treatments. Nevertheless, the transmissibility of bona fide prions is unique, and PrDs should be considered as distinct from other PMDs.
\end{abstract}

DOI: https://doi.org/10.1038/s41576-018-0011-4

Posted at the Zurich Open Repository and Archive, University of Zurich

ZORA URL: https://doi.org/10.5167/uzh-151651

Journal Article

Accepted Version

Originally published at:

Scheckel, Claudia; Aguzzi, Adriano (2018). Prions, prionoids and protein misfolding disorders. Nature Reviews. Genetics, 19(7):405-418.

DOI: https://doi.org/10.1038/s41576-018-0011-4 


\section{Prions, prionoids, and protein misfolding disorders}

2 Claudia Scheckel and Adriano Aguzzi

3

4 Institute of Neuropathology,

5 University of Zurich,

$6 \quad$ Schmelzbergstrasse 12

$7 \quad$ CH-8091 Zurich, Switzerland

8

9 Correspondence to AA

10 e-mail: adriano.aguzzi@usz.ch 


\section{ABSTRACT}

2 Prion diseases are progressive, incurable and fatal neurodegenerative conditions. The term "prion" was

3 first nominated to express the revolutionary concept that a protein could be infectious. We now know

4 that prions consist of $\mathrm{PrP}^{\mathrm{Sc}}$, an aggregated form of the cellular protein $\mathrm{PrP}^{\mathrm{C}}$. Over the years, the term

5 has been semantically broadened to describe aggregates irrespective of their infectivity and the prion

6 concept is now being applied, perhaps overenthusiastically, to all neurodegenerative diseases that

7 involve protein aggregation. Indeed, recent studies suggest that prion diseases (PrDs) and protein

8 misfolding disorders (PMDs) share some common disease mechanisms, which could have implications

9 for potential treatments. Nevertheless, the transmissibility of bona fide prions is unique and PrDs should

10 be considered as distinct from other PMDs.

\section{[H1] INTRODUCTION}

Prion diseases [G] (PrDs), which are also termed transmissible spongiform encephalopathies (TSEs), are fatal neurodegenerative diseases characterized by neuronal loss, vacuolation, astrocyte activation and microglia activation. PrDs can undergo extraordinarily long incubation periods ranging from years to decades. However, when the clinical signs become evident, the course of the disease is often dramatic $^{1}$.

The term prion [G] was originally coined to describe the infectious proteinaceous agent causing $\mathrm{PrDs}^{2}$, and did not have a specific biophysical meaning attached to it. Subsequently, prions were shown to consist primarily of $\operatorname{PrP}^{\mathrm{Sc}}{ }^{3}$, aggregates [G] of the cellular prion protein $\operatorname{PrP}^{\mathrm{C}}{ }^{4}$. Misfolded $\operatorname{PrP}^{\mathrm{C}}$ is incorporated into heterodisperse, fibrillary beta-sheet rich structures, which are termed amyloids. Other proteins can also form amyloids, which have been associated with numerous other protein-misfolding disorders (PMDs) [G].

24 Prions are thought to multiply by a nucleation-and-fragmentation process akin to the growth of crystals ${ }^{5,6}$ : highly ordered $\mathrm{PrP}^{\mathrm{Sc}}$ oligomers incorporate endogenous $\mathrm{PrP}^{\mathrm{C}}$, thereby growing in size (Figure 1). Large $\mathrm{PrP}^{\mathrm{Sc}}$ aggregates may then decay into smaller fragments of various sizes, each of 
1 which can restart the nucleation-fragmentation cycle. The minimal self-replicating unit of misfolded

2 aggregates is called a propagon $[\mathbf{G}]^{7}$. A propagon reflects the biological activity of the prion rather than

3 a specific structural entity. Accordingly, a prion sample containing many smaller oligomers has a higher number of propagons than one containing larger fibrils. Prions show a remarkable resistance to proteases, heat and decontamination methods, which has proven to be a major challenge for the prevention of PrDs. Yet, protease resistance of prions only correlates loosely with infectivity: the majority of infectivity is associated with protease-sensitive oligomers ${ }^{8}$.

8 The process of generating infectious $\mathrm{PrP}^{\mathrm{Sc}}$ has been reproduced in vitro ${ }^{9}$, which has provided substantial 9 evidence that prion infectivity depends on $\mathrm{PrP}^{\mathrm{Sc}}$. In vitro amplification of $\mathrm{PrP}^{\mathrm{Sc}}$ allows the detection of minute amounts of prions and has been adopted for the diagnosis of PrDs (Box 1). Since the incorporation of $\operatorname{PrP}^{\mathrm{C}}$ is required for prion replication, mice lacking $\operatorname{PrP}^{\mathrm{C}}$ are resistant to prion infection ${ }^{4,10,11}$. While it is widely accepted that $\mathrm{PrP}^{\mathrm{Sc}}$ is an essential component of the infectious agent, additional co-factors are likely to play a part in prion replication in vivo ${ }^{12}$. Interestingly, while $\operatorname{PrP}^{\mathrm{C}}$ is abundantly expressed throughout the body, prion deposition as well as vulnerability to prion toxicity varies profoundly between tissues ${ }^{13}$. The observation that different cell types show distinct susceptibilities to prion infection and toxicity further suggests that additional components (proteins or otherwise) can affect the ability of prions to replicate and/or exert toxicity.

An increasing number of neurodegenerative disorders including Alzheimer's Disease (AD), Parkinson's Disease (PD) and amyotrophic lateral sclerosis (ALS), but also metabolic diseases and cancer have now been linked to protein misfolding and aggregation ${ }^{14,15}$. While protein aggregation may conceivably lead to protein inactivation via sequestration, the aggregates themselves can exert toxicity by interfering with intracellular functions or cell-to-cell signaling. Several protein aggregates linked to these disorders have been shown, like prions, to undergo cycles of nucleation and fragmentation. Unlike for prions, no inter-individual transmissibility has yet been demonstrated for any of these aggregates we therefore introduced the term "prionoids" $[\mathbf{G}]^{14,15}$ to describe these aggregates. However, shared characteristics with prions combined with the high prevalence of many prionoid-mediated PMDs have raised concerns related to the handling of prionoids ${ }^{15}$. 
In this Review, we provide an overview of the current understanding of prions and PrDs. We discuss similarities and important distinctions between PrDs and prionoid-mediated PMDs and their respective aggregates, and comment on the implications for the diagnosis, treatment and containment of these diseases. Finally, we highlight different therapeutic strategies that aim to prevent or eliminate pathological protein aggregation and are therefore relevant to PMDs in general.

\section{[H1] PRION DISEASE}

[H2] Forms of prion diseases. Human PrDs can be grouped into genetic, sporadic and acquired forms and have an overall incidence of 1-2 cases per million. All PrDs are characterized by an accumulation of $\mathrm{PrP}^{\mathrm{Sc}}$ in the central nervous system, either in the form of plaques or as synaptic deposits. Genetic PrDs (gPrDs) are all caused by mutations in the PRNP gene, which encodes $\operatorname{PrP}^{\mathrm{C}}$, and include genetic Creutzfeldt-Jakob disease (gCJD), Fatal Familial Insomnia (FFI) and Gerstmann-Straeussler-Scheinker Syndrome (GSS) (Figure 2). By contrast, sporadic CJD (sCJD) and sporadic FFI have an unknown etiology despite sCJD being the most common form of human PrDs, accounting for $85-90 \%$ of all cases. Acquired PrDs are induced by transmission of pre-existing prions and they include: variant CJD (vCJD), which is caused by bovine prions ${ }^{16}$; iatrogenic CJD (iCJD), which is transmitted by medical procedures; and kuru in Papa New Guinea, which is acquired as a result of cannibalistic rituals. PrDs occur in many mammalian species, most notably as bovine spongiform encephalopathy (BSE or mad cow disease $)^{17}$, scrapie in sheep and goats, and chronic wasting disease in deer and $\mathrm{elk}^{18}$. Prions from one species are usually less infectious to individuals of another species, reflecting a species barrier. However, PrDs can also be transmitted between species, albeit with variable efficiency ${ }^{19}$.

[H2] $\operatorname{PrP}^{C}$ is required for prion diseases to occur. Although $\operatorname{PrP}^{\mathrm{C}}$ was first linked to PrDs decades ago, its cellular function is not entirely understood. The 253 amino acid membrane protein (Figure 2a) is evolutionarily conserved from birds to mammals and comprises: a flexible tail at the $\mathrm{N}$-terminus, which spans two charge clusters ( $\mathrm{CC} 1$ and $\mathrm{CC} 2)$; an octapeptide repeat region (OR); a hydrophobic domain $(\mathrm{HD})^{20}$; and a C-terminal globular domain, consisting of three $\alpha$-helices and two short antiparallel $\beta$ sheets ${ }^{21}$. A glycosyl phosphoinositol (GPI) modification at residue 230 anchors $\operatorname{PrP}^{\mathrm{C}}$ to the plasma 
membrane. Addition of oligosaccharides at residues 181 and 197 gives rise to different glycosylated forms of $\operatorname{PrP}^{\mathrm{C}}$, and facilitates the correct localization of $\operatorname{PrP}^{\mathrm{C}}$ to the plasma membrane. Initial functional analysis performed in Prnp deficient mice with a mixed genetic background suggested a number of functions for $\mathrm{PrP}^{\mathrm{C}}$, including a role in regulating long-term potentiation, which underlies memory formation $^{22}$. However, careful replication of experiments in perfectly co-isogenic mice has clarified that some phenotypes, such as enhanced phagocytosis, are due to polymorphisms [G] in genes flanking $\operatorname{Prnp}^{23}$, including Sirpa ${ }^{24}$, which encodes the signal regulatory peptide $\alpha$. Nonetheless, all Prnp deficient mice develop a chronic demyelinating neuropathy ${ }^{23,25}$, and $\operatorname{PrP}^{\mathrm{C}}$ has been shown to promote myelin homeostasis by activating the G protein-coupled receptor Gpr126 on Schwann cells ${ }^{26}$. The availability of co-isogenic Prnp deficient mice now allows a thorough reassessment of functions previously attributed to $\operatorname{PrP}^{\mathrm{C}}$, and is likely to reveal novel $\operatorname{PrP}^{\mathrm{C}}$ functions.

[H2] Mutations in PRNP are linked to genetic prion disease. All known gPrDs are caused by mutations in the PRNP gene, which usually have full penetrance [G] (Figure 2b). Most of the mutations are localized in the second and third alpha helix, and are thought to induce $\operatorname{PrP}^{\mathrm{C}}$ misfolding and, ultimately, pathological aggregates via a mechanism that is poorly understood. GSS is characterized by large, multicentric amyloid plaques and the most commonly associated mutation is a proline-to-leucine substitution at codon $102(\mathrm{P} 102 \mathrm{~L})^{27}$. By contrast, FFI is caused by an asparagine and a methionine at positions $178(\mathrm{D} 178 \mathrm{~N})$ and 129 , respectively ${ }^{28}$. The D178N mutation has additionally been shown to cause $\mathrm{gCJD}$, if in conjunction with a valine at residue $129\left(\mathrm{ref}^{29}\right)$. The polymorphism at position 129 has since been observed to affect the aggregation propensity of $\mathrm{D} 178 \mathrm{~N}$ mutant $\operatorname{PrP}^{\mathrm{C}}$ into amyloid fibrils in vitro, but the underlying mechanism is $u_{k n o w n}{ }^{30}$. Several other point mutations, most notably $\mathrm{E} 200 \mathrm{~K}^{31}$ and $\mathrm{V}_{210 \mathrm{I}^{32}}$, have been associated with gCJD (Figure 2), many of which reside in the globular domain at the C-terminus and disrupt potential salt bridge or hydrogen bonding interactions ${ }^{33}$. In addition, insertions of additional octapeptide repeats cause gCJD and affect the aggregation propensity of $\operatorname{PrP}{ }^{\mathrm{C}}$

[H2] PRNP polymorphisms modulate susceptibility to prion disease. PrDs are classified as a single 
homogenous disease, however it has become evident that prions can cause many different molecular and clinical phenotypes, possibly reflecting the existence of distinct structural assemblies, also termed prion strains $[\mathbf{G}]^{34}$. Indeed, PRNP polymorphisms have been shown to influence the predisposition towards sporadic, variant and genetic PrDs (Figure 2b) in a prion-strain dependent manner. An important disease-modifying polymorphism exists at codon 129, which can encode either valine (V) or methionine $(\mathrm{M})^{35}$. Allele frequencies vary between populations: in the UK, $47 \%$ of the normal population are heterozygous at this locus, and $42 \%$ and $11 \%$ are homozygous for $\mathrm{M}$ and $\mathrm{V}$, respectively ${ }^{36}$. Homozygosity for either amino acid predisposes to SCJD and leads to an earlier onset of $\mathrm{gPrD}^{37}$ and all but one out of $>300 \mathrm{vCJD}$ patients identified to date have been homozygous for methionine at codon $129\left(\mathrm{ref}^{38}\right)$. Moreover, three of the four individuals that died of vCJD after having received contaminated blood transfusions were homozygous for methionine at codon $129\left(\mathrm{ref}^{39,40}\right)$. By contrast, the fourth individual was $129^{\mathrm{Met} / \mathrm{Val}}$ heterozygous, displayed prion protein deposition only in the spleen and lymph nodes, showed no signs of a neurological disorder, and died of a ruptured abdominal aortic aneurysm ${ }^{41}$. This suggests that while subjects with MV and VV versions of PRNP might be able to succumb to vCJD infection, the incubation time in these patients will be significantly longer. Consequently, it has been argued that a large number of individuals may be infected with $\operatorname{PrD}$ but remain asymptomatic, and that these individuals might unknowingly transmit the disease during the prolonged incubation periods. While this is theoretically possible, no evidence has come forward to support this idea. Interestingly, MV heterozygosity confers protection against vCJD but not against kuru $^{42}$.

A different polymorphism has been found to affect susceptibility to SCJD in the Japanese population. Codon 219 can encode either glutamic acid or lysine, and 14\% of the population has been reported to be heterozygous at this codon (the remaining $86 \%$ are homozygous for glutamic acid). However, no heterozygous SCJD patients have been identified to date, which suggests that heterozygosity at codon 219 may protect individuals from developing $\mathrm{SCJD}^{43}$. More recently, another protective polymorphism, this time at codon 127 , has been described specifically in populations from kuru-exposed regions. Interestingly, heterozygosity for glycine and valine was observed in non-diseased individuals but not 
in patients with kuru, who were all homozygous for valine ${ }^{42}$. The G127V variant was further assessed in mice, revealing that it conferred protection not only against kuru but also against classical CJD prion strains $^{44}$.

[H2] Non-PRNP genetic susceptibility factors. The low incidence of PrDs renders the discovery of genetic modulators of PrD a major challenge, and genome-wide association studies revealed only $P R N P$ to being highly associated with a risk for all human $\operatorname{PrDs}^{45-47}$. A recent study aimed to quantify $\operatorname{PrD}$ penetrance by leveraging previously published datasets. The authors collected sequencing data from $\sim 16,000 \operatorname{PrD}$ cases from around the world, constituting a substantial fraction of all documented $\operatorname{PrD}$ cases to date. The PrD cases were then compared to a control group consisting of $\sim 61,000$ exomes from unrelated individuals and GWAS data from $\sim 530,000$ customers of the genetic analysis company, 23andMe. Remarkably, in these large control population cohorts, 63 rare PRNP genetic variants previously reported to cause PrD were observed 30 times more often than expected based on the incidence of gPrDs. The overrepresentation of $P R N P$ mutations was not limited to specific ethnic or demographic groups but was observed in populations of diverse ancestries ${ }^{48}$. While several of these variants might in fact represent benign or low-risk variants, this data nonetheless suggests the existence of non-genetic factors that affect disease manifestation. Environmental factors have been found to affect the pathogenesis of most diseases characterized to date and are therefore certain to also contribute to PrDs. It is also possible that some healthy subjects with $P R N P$ mutations have developed mechanisms that protect them from developing disease. One tantalizing hypothesis is that these individuals produce $\mathrm{PrP}^{\mathrm{Sc}}$-specific antibodies that shield them against the pathogenic effects of PRNP mutations.

\section{[H1] PRIONOID-MEDIATED DISORDERS}

The term 'prion' has been liberally used for many protein aggregates. Yet bona fide infectivity of these aggregates, exemplified by serial transmissibility through consecutive hosts to prove unlimited selfreplication of the agent, has been rarely claimed. Mammalian protein aggregates that are defined as prions will need to be handled in accordance with high level biosafety measures, which may include 
the requirement for BSL3 laboratories. As we believe that the necessity of such measures should be determined by data rather than imprecise semantics, we have proposed that the term 'prionoid' should be used to describe misfolded protein aggregates for which transmissibility between individuals has not yet been demonstrated ${ }^{14,15}$.

[H2] Non-neuronal prionoids. The transcriptional regulator p53 has long been known to be a tumor suppressor, and p53 mutations have been detected in $>50 \%$ of human malignant tumors. More recently, mutated p53 has been shown to form aggregates in tumors and cancer cell lines ${ }^{49,50}$. Mutations in the p53 DNA binding domain destabilize its tertiary structure, leading to the exposure of an aggregationnucleating segment (also termed amyloid adhesive segment) that is normally buried within the hydrophobic core of the protein. The exposure of this fragment is then thought to trigger the aggregation of wild type p53 and its paralogs, p63 and p73, into beta-sheet-like structures, which form large cytoplasmic inclusions ${ }^{49}$. Additionally, p53 aggregates have been shown to spread between cells in a manner that is similar to cell-to-cell transmission of prions ${ }^{51,52}$. Indeed, mice and patients harboring $\mathrm{p} 53$ aggregation mutations have higher tumor numbers than those with non-agreggation mutations, and tumor formation is dependent on the presence of aggregation-prone $\mathrm{p} 53^{53}$. These findings demonstrate that $\mathrm{p} 53$ is a bone fide prionoid, and indicate that $\mathrm{p} 53$ aggregation and cell-to-cell transmission play an important role in metastasis formation.

Misfolded aggregates of islet amyloid polypeptide (IAPP) accumulate in the pancreas and are commonly observed in type 2 diabetes (T2D) patients. IAPP aggregates that have either been generated in vitro or obtained from pancreatic samples induce the misfolding and deposition of endogenous IAPP in mice, confirming IAPP to be a prionoid. Importantly, IAPP deposition is accompanied by typical T2D traits such as hyperglycemia, impaired glucose tolerance and a decrease in pancreatic $\beta$-cells, indicating that IAPP accumulation plays an important role in T2D manifestation ${ }^{54}$.

Although protein aggregation usually occurs in specific organs, several PMDs are characterized by systemic aggregate deposition. Examples include aggregation of immunoglobulin light chain in amyloid light (AL) amyloidosis, transthyretin in familial amyloid polyneuropathy, $\beta 2$-microglobulin in 
1 dialysis-related amyloidosis and amyloid A (AA) in reactive amyloid A amyloidosis. It has been

5 [H2] Prionoids linked to neurodegeneration. Aggregates of $\alpha$-synuclein have been linked to multiple suggested that transmission of these aggregates can occur between multiple species, indicating that they might not only qualify as prionoids but even as prions, with the evidence being strongest for $\mathrm{AA}^{55}$.

neurodegenerative diseases, including multiple system atrophy (MSA), dementia with Lewy bodies (DLB) and PD. Intracerebral inoculation of mice with brain homogenate from MSA patients induces $\alpha$-synuclein phosphorylation and aggregation and neurological phenotypes, even upon serial propagation $^{56,57}$. The detection of infectivity after multiple passages is a hallmark of prions, suggesting that $\alpha$-synuclein might indeed be a prion. However, the development of CNS dysfunction in these mice is dependent on the presence of a hemizygous transgene encoding an aggregation-prone mutant form of human $\alpha$-synuclein, which by itself did not cause neurological dysfunction. This raises questions as to whether only mutated $\alpha$-synuclein can be incorporated into $\alpha$-synuclein aggregates, or whether the requirement for a transgene reflects an inter-species barrier similar to that observed for known prions ${ }^{58}$. Interestingly, neither PD nor DLB patient homogenates could induce neurological dysfunction in mice hemizygous for the mutated human $\alpha$-synuclein transgene. This result indicates that the $\alpha-$ synuclein aggregates from different diseases not only vary in the cell type in which they are found (neuronal inclusions in DLB and PD; glial inclusions in MSA), but also in their potential to be propagated in mice. MSA-associated $\alpha$-synuclein inclusions in glia cells might be more infectious due to their glial origin, however MSA homogenates can also induce $\alpha$-synuclein aggregation in neurons ${ }^{57}$. A recent study showed that even spinal cord homogenates prepared from wild-type and $\alpha$-synuclein deficient mice could induce $\alpha$-synuclein deposits and CNS dysfunction in mice hemizygous for the mutated human $\alpha$-synuclein transgene ${ }^{59}$. This observation suggests that these homogenates contain a component that can trigger $\alpha$-synuclein pathology in the presence of mutated human $\alpha$-synuclein. Perhaps even more worrisome are reports on human PD patients that received embryonic neuronal transplants. Despite the young age of the transplanted neurons, the grafts displayed synuclein inclusions 
1 10-24 years post-transplantation, showing that synuclein aggregates were able to spread from host to

2 graft in a prion-like manner ${ }^{60-64}$.

$3 \mathrm{AD}$ is characterized by amyloid- $\beta(\mathrm{A} \beta)$ deposition, which has been shown to follow a stereotypic 4 sequence that involves progressively larger brain areas ${ }^{65}$. The injection of human $\mathrm{AD}$ brain 5 homogenates containing $A \beta$ aggregates causes cerebral $\beta$-amyloidosis and pathology in mice. 6 Importantly, $A \beta$-immunodepleted homogenates failed to induce lesions, suggesting that induction of 7 amyloidosis is dependent on $A \beta^{66}$. However, similar to synuclein, the induction of $A \beta$ pathology in mice depends on the overexpression of $A \beta$. Further experiments demonstrated that $A \beta$ alone is indeed sufficient for self-propagation in vitro and that the in vitro generated $A \beta$ aggregates are able to induce amyloidosis ${ }^{67}$. Interestingly, it has recently been shown that eight deceased individuals that contracted iCJD via human growth hormone (hGH) injections also display $\mathrm{A} \beta$ pathology ${ }^{68}$. These findings were confirmed in a separate study, which additionally detected $\mathrm{A} \beta$ accumulation in $12 \mathrm{hGH}$ recipients that died of a cause other than $\mathrm{CJD}^{69}$. It remains unclear if the hGH samples were the source of $\mathrm{A} \beta$ aggregation, and the patients did not show any signs of tau pathology, a second hallmark of AD. Nonetheless, these subjects might represent the first known cases of iatrogenic $A \beta$ transmission. Consistently, iCJD caused by dural grafting has been shown to be associated with $\mathrm{A} \beta$ pathology ${ }^{70}$, making $\mathrm{A} \beta$ a candidate prion.

Tau pathology is not only characteristic of AD but also of multiple other neurodegenerative disorders. Similarly to other prionoids, Tau aggregates spread throughout the brain in an orderly fashion that is characteristic for each tauopathy, ultimately leading to distinct Tau pathologies ${ }^{71}$. However, the cause of Tau aggregation in the different diseases is still mostly unknown. The injection of AD homogenates containing Tau aggregates into mice has been shown to induce Tau aggregation, even in wildtype mice $^{72}$. Furthermore, a recent study revealed that some hGH-related iCJD patients display tau pathology that seems to be linked to Tau contaminants in the respective hGH samples ${ }^{73}$. While these results might have far-reaching implications for the handling of tauopathy patients and samples, further validation is required to confirm the transmission of Tau aggregates between individuals before it can be considered 
a prion.

\section{[H1] MEDIATORS AND MODULATORS OF TOXICITY}

[H2] Mechanisms underlying aggregation differ between protein misfolding disorders. The formation

of extracellular and intracellular protein aggregates can exert toxicity both in the extracellular space and

within the cell. Furthermore, aggregation goes hand in hand with the sequestration of monomeric protein, which can cause additional deleterious effects. For example, the deleterious effects of p53 aggregation in cancer seem to be associated with sequestration of p 53 rather than with the aggregates ${ }^{49}$. By contrast, the toxicity of PMDs affecting the nervous system seems to be exerted by the aggregates themselves. Some of the aggregated proteins possess a low-complexity domain that is intrinsically disordered and enriched for polar uncharged residues, particularly glutamine and asparagine ${ }^{74}$. Such domains have been called "prion-like" owing to their similarity to certain nucleating proteins of yeast. However, $\operatorname{PrP}^{\mathrm{C}}$ lacks such a domain, indicating that the early aggregation events leading to the formation of prions and prionoids are distinct. Indeed, certain proteins involved in neurodegeneration undergo phase demixing $[\mathbf{G}]^{75}$, a recently discovered aggregation modality that is often reversible and fundamentally different from the aggregation of prions.

While the cause, the location and the aggregates themselves differ, certain parallels between the different PMDs can be legitimately drawn. For instance, oligomers of misfolded proteins are more pathogenic than higher-order structures such as protofilaments and fibrils ${ }^{8}$, possibly because of their higher stoichiometry. Furthermore, disparate aggregates often trigger converging pathways of toxicity. Hence insights gained for one PMD may be relevant for others.

[H2] Uncoupling protein aggregation and toxicity. Neurons devoid of $\mathrm{Pr}^{\mathrm{C}}$ do not develop spongiform changes even when chronically exposed to prions in vivo ${ }^{11}$, suggesting that $\operatorname{Pr}^{\mathrm{C}}$ is not only needed for prion replication, but that it also functions as a mediator of prion toxicity. Additionally, this observation indicates that extracellular PrP deposits are not toxic per se but that binding of aggregates to membranebound $\operatorname{PrP}^{\mathrm{C}}$ is required to induce toxicity within cells. This hypothesis is further supported by the observation that protective $\operatorname{PrP}^{\mathrm{C}}$-directed antibodies prevent neurotoxicity without affecting prion Page | 11 
1 accumulation ${ }^{76}$. Antibodies against $\operatorname{PrP}^{\mathrm{C}}$ were shown to be protective against $\operatorname{PrD}$ in mice almost two

2 decades $\operatorname{ago}^{77}$ and a series of monoclonal antibodies targeting different domains of $\operatorname{PrP}^{\mathrm{C}}$ has since

3 proven useful for studying the mechanism of prion-induced toxicity ${ }^{78}$. Protective antibodies binding to

4 the flexible tail (FT) of $\operatorname{PrP}^{\mathrm{C}}$, as well as FT deletion mutants of $\operatorname{PrP}^{\mathrm{C}}$, revealed that $\mathrm{FT}$ is required for

5 prion replication in vivo and is the effector domain of $\mathrm{PrP}^{\mathrm{Sc}}$-mediated toxicity ${ }^{76}$. By contrast, antibodies

6 targeting the globular domain $(\mathrm{GD})$ of $\mathrm{PrP}^{\mathrm{C}}$ induce transcriptional changes and phenotypic changes

7 remarkably similar to those induced by prions, including neuronal loss, astrogliosis, microglial

8 activation, and spongiosis ${ }^{79}$. Anti-GD antibodies and prions also activate similar toxicity pathways ex

9 vivo ${ }^{76,79,80}$. However, anti-GD antibodies fail to induce aggregates, infectious prions and prion

pathology in $v i v o^{81}$, indicating that they act on a pathway downstream of prion replication. The fact that

$\mathrm{PrP}^{\mathrm{C}}$ antibodies can be protective or toxic, depending on the targeted domain, has shed light on the mechanisms of prion-induced toxicity and has far-reaching implications for immunotherapy of not only

PrDs but diseases more generally.

[H2] Aggregation-induced toxicity. The observation that $\operatorname{PrP}^{\mathrm{C}}$ is required for toxicity suggests that precluding protein aggregates from entering the cell might prevent the induction of toxicity and neuronal loss. Several mechanisms have been proposed to explain how aggregates enter and spread between cells, which involve exosomes ${ }^{82,83}$, nanotubes $^{84}$ or receptor-mediated internalization $^{8}$.

However, the mechanisms by which extracellular aggregates initiate intracellular toxicity are less clear. One possibility is that aggregates alter receptor-mediated signaling pathways. Aberrant glutamate signaling has been linked to $\operatorname{PrD}^{85-88}$, which is further supported by the observation that $\operatorname{PrP}^{\mathrm{C}}$ inhibits $\mathrm{N}$-methyl-D-aspartate receptors (NMDAR) and attenuates excitotoxicity $[\mathbf{G}]^{89}$. A $\beta$ oligomers inhibit long-term potentiation (LTP) and impair synaptic plasticity, and several receptors have been suggested to play a role in internalizing $\mathrm{A} \beta$, including $\operatorname{PrP}^{\mathrm{C}}$. Indeed, it has been claimed that $\operatorname{PrP}^{\mathrm{C}}$ is required for $\mathrm{A} \beta$-induced LTP in hippocampal slices ${ }^{90}$ and for memory impairment in vivo ${ }^{91}$. mGluR5 may act as a co-receptor for $\mathrm{A} \beta$ binding to $\operatorname{PrP}^{\mathrm{C}}$ 92,93, with subsequent NMDAR activation leading to synaptic spine loss ${ }^{94,95}$. Accordingly, increased glutamate signaling has been seen in a mouse AD model ${ }^{96,97}$ and genetic depletion of mGluR5 reduces $\mathrm{AD}$ pathology in vivo ${ }^{98}$. However, the role of $\operatorname{PrP}^{\mathrm{C}}$ in mediating Page | 12 
$1 \mathrm{~A} \beta$ toxicity is contentious. Several studies suggest that $A \beta$ oligomers can induce synaptic defects and 2 impair long-term memory formation independently of $\operatorname{PrP}^{\mathrm{C}} 99,100$ and neither $\operatorname{PrP}^{\mathrm{C}}$ ablation nor overexpression modified the synaptic pathology in two mouse AD models ${ }^{101,102}$. These discrepancies can likely be explained by differences in study design, including the use of different mouse AD models, and will almost certainly be resolved by future studies. More recently, it has been suggested that $\operatorname{Pr} \mathrm{P}^{\mathrm{C}}$ also mediates the uptake of $\alpha$-synuclein oligomers ${ }^{103,104}$. Oligomeric $\alpha$-synuclein is highly neurotoxic and impairs hippocampal LTP via NMDAR activation ${ }^{105}$. The interaction of $\alpha$-synuclein and $\operatorname{PrP}^{\mathrm{C}}$ at the post-synapse activates NMDAR via mGluR5, and triggers synaptic defects and cognitive impairment ${ }^{104}$.

By contrast, intracellular aggregates might mediate toxicity by affecting subcellular compartments, such as the endoplasmic reticulum (ER). $\operatorname{PrP}^{\mathrm{C}}$ undergoes posttranslational modifications in the ER and Golgi before localizing to cholesterol-rich lipid rafts at the plasma membrane. $\mathrm{PrP}^{\mathrm{C}}$ has a short half-life ${ }^{106}$, and approximately $10 \%$ is misfolded and subsequently degraded by the ubiquitin-proteasome system (UPS) after retrograde ER translocation ${ }^{107,108}$. By contrast, pathogenic mutations linked to gPrD cause $\operatorname{PrP}^{\mathrm{C}}$ to aggregate and remain in the ER and Golgi ${ }^{109-113}$. Dysfunctional and misfolded proteins are usually ubiquitinated and degraded by the UPS, and it has been suggested that this process is inhibited by misfolded $\operatorname{PrP}^{114-116}$. The resulting buildup of dysfunctional proteins eventually causes ER stress and activates the unfolded protein response (UPR). One consequence of UPR induction is a global shutdown of translation, mediated by phosphorylation of PERK, which in turn phosphorylates and deactivates the eukaryotic translation initiation factor eIF $2 \alpha$. Prion infection causes a global repression of protein synthesis via eIF2 $\alpha$ phosphorylation, ultimately leading to synaptic dysfunction and neuronal loss. Interestingly, globally increasing translation via eIF $2 \alpha$ dephosphorylation reduces neuronal toxicity and increases the survival time of prion-exposed mice, whereas increasing eIF $2 \alpha$ phosphorylation further aggravates prion-induced pathology ${ }^{117}$. ER stress, as well as activation of the UPR and PERK, have also been reported in several other PMDs including AD, PD, ALS, and tauopathy ${ }^{118-123}$.

[H2] Differential vulnerability of cells and tissues. Protein aggregation has been linked to several nonPage | 13 
neuronal disorders, including metabolic diseases and cancer, but the brain is the organ most vulnerable to protein aggregation. While PMD aggregates are thought to directly exert toxicity on the brain, several of their substrates, including $\operatorname{PrP}^{\mathrm{C}}$, amyloid precursor protein, $\alpha$-synuclein and tau, are not exclusively expressed in the nervous system ${ }^{124-126} \cdot \mathrm{PrP}^{\mathrm{C}}$ is expressed at moderate levels in heart, muscle and spleen, and prions have been shown to accumulate in these tissues. In fact, prions replicate in peripheral lymphoid organs before they reach the brain, and mice that lack B lymphocytes, or follicular dendritic cells (FDCs), cannot succumb to PrD if infected by peripheral administration ${ }^{127}$. These studies demonstrate that prion infectivity and pathogenesis are not restricted to the brain, but that prion-diseased mice, as well as patients, are likely to succumb to fatal neuronal defects before non-neuronal phenotypes can manifest. On the other hand, certain organs never acquire prion replication competence, even when forced by transgenesis to express high levels of $\operatorname{PrP}^{\mathrm{C}}{ }^{128}$. It is likely that a combination of substrate expression and exceptional vulnerability of neurons account for the predominant neuronal phenotype of not only PrD, but also other neurodegenerative PMDs including AD, PD, and ALS.

Each neurodegenerative disease displays a distinct pathology within the central nervous system, which is determined by a variety of factors, including differences in the aggregate structure and localization, and selective vulnerabilities of cells and brain regions (Box 2). For example, $\alpha$-synuclein aggregates are present as cytoplasmic inclusions in multiple neurodegenerative diseases including PD, DLB and MSA, and yet the affected cell types and brain regions vary substantially between the different diseases. The underlying cause for the pathological differences in $\alpha$-synuclein deposition is unknown but, not surprisingly, they result in distinct clinical manifestations ${ }^{129}$. While pathological changes are usually homogenous within one neurodegenerative disease, PrDs are characterized by a spectrum of different pathologies and clinical features. One cell type that is particularly vulnerable to prion deposits and other protein aggregates is parvalbumin positive inhibitory neurons, which are distinguished by a high firing rate and a high metabolic rate, leading to increased exposure to oxygen radicals and intracellular damage. Severe selective loss of parvalbumin neurons in the cortex and hippocampus has been observed in CJD, GSS and kuru ${ }^{130-132}$. By contrast, FFI pathology is mostly focused on the thalamus and patients show only a moderate loss of cortical parvalbumin neurons ${ }^{132}$. The differential vulnerability of cells and 
brain regions indicates that aggregation-induced toxicity can be modulated by the expression of cofactors, such as receptors and chaperones ${ }^{12}$. Future studies focusing on single cells, or at least single cell types, will therefore be of particular importance in deciphering why various cell types undergo distinct fates upon exposure to protein aggregates. The remarkable phenotypic heterogeneity of PrDs is further attributed to the different biochemical and neuropathological profiles of the various prion strains, which seem to be able to exert differential toxicity, presumably through their interplay with additional factors ${ }^{12}$.

Immune cells are critical for prion replication and spreading, especially when prions are administered via the peripheral route. Similarly to PrP prions, the induction of $\alpha$-synuclein pathology seems to be strongly dependent on the source of the injected homogenate and the route of administration. Mice inoculated intracerebrally with homogenates containing $\alpha$-synuclein aggregates that have been taken from MSA patients display a more rapid disease progression compared with intraperitoneally inoculated mice $^{133}$. A $\beta$ aggregates were recently shown to be able to enter the brain via the blood stream using a parabiosis [G] model in which wildtype mice showed hippocampal impairment upon being paired with transgenic $\mathrm{AD}$ mice ${ }^{134}$. This observation is in contrast to prions, which do not enter the nervous system via the blood stream but via peripheral, mostly sympathetic, nerves ${ }^{135,136}$.

Post-translational modifications have been suggested to impact protein aggregation, replication and toxicity. Different PrDs have been linked to distinct ratios of mono- and di-glycosylated $\operatorname{PrP}^{\mathrm{C}}{ }^{137}$, and several post-translational modifications have also been implicated in $\mathrm{AD}$ pathogenesis. For instance, accumulation of N-terminally truncated and pyroglutamated $\mathrm{A} \beta$ precedes the deposition of nonmodified $A \beta^{138}$, and inhibition of glutaminyl-cyclase, which generates pyroglutamated $A \beta$, improves neuronal defects and attenuates $\mathrm{AD}$ pathology in mice $^{139}$. Nitrosative stress has also been shown to be induced in $\mathrm{AD}$, which leads to NOS2 mediated addition of 3-nitrotyrosine to proteins, including $\mathrm{A} \beta^{140,141}$. Nitrated $\mathrm{A} \beta$ can then induce and accelerate amyloidosis and exacerbate memory loss, both of which can be prevented by NOS2 inhibition. Hence targeting disease-specific posttranslational modifications of aggregates might represent a promising approach to combat PMDs.

[H2] Chaperones. Chaperones linked to protein synthesis (CLIPs) stabilize and correctly fold newly Page | 15 
synthesized proteins, whereas heat shock proteins (HSPs) recognize misfolded proteins (Figure 1).

CLIPs are downregulated and HSPs are induced in cells of the aging brain or in response to stress, which protects the cells against misfolded protein toxicity. Stress, aging and mutations can induce protein misfolding and expose otherwise buried aggregation-prone domains. If not targeted by chaperones for either re-folding or proteasomal degradation, these misfolded proteins start to aggregate into higher-order structures that are resistant to proteasomal degradation ${ }^{142}$. Notably, different HSPs can have opposing effects on protein aggregation. For example, whereas HSP70 promotes protein degradation via the ubiquitin proteasome system, HSP90 stabilizes proteins and inhibits their ubiquitination. The activity of these two proteins is regulated in a coordinated manner, with inhibition of HSP90 leading to HSP70 activation via HSF1. Compared with wildtype mice, mice lacking functional HSF1 have a shortened lifespan when inoculated with prions but the resulting behavioral and pathological changes are similar ${ }^{143}$, which suggests that HSF1 exerts its protective function only after the onset of clinical symptoms. The co-ordinated regulation of HSP70 and HSP90 makes these chaperones interesting therapeutic targets. Indeed, HSP90 inhibitors have been shown to prevent aggregation and toxicity of many aggregates in cells and mice, including p53, $\alpha$-synuclein, tau and huntingtin ${ }^{53,144-147}$, probably reflecting consequences of HSP90 inhibition as well as HSP70 activation. Several chaperones have been shown to be upregulated in PrD patients, including GRP78 and GRP58 (ref ${ }^{148,149}$ ). GRP78 (also known as BiP or HSP5A) prevents the aggregation of misfolded proteins in the ER, including PrP and $\mathrm{A} \beta$, and targets protein aggregates for proteasomal degradation ${ }^{112,150}$. Accordingly, GRP78 overexpression reduces prion replication, and GRP78 reduction leads to increased prion replication and accelerated PrD progression ${ }^{151}$. Similar results have been reported for GRP58 (also termed ERp57) with its overexpression conferring neuroprotection and its downregulation leading to increased prion induced toxicity ${ }^{152}$.

Another chaperone of interest with respect to protein aggregation is the yeast chaperone Hsp104, a prion disaggregase that acts together with Hsp70 and Hsp40 to release correctly folded proteins from aggregates ${ }^{153}$. Yeast prions are highly sensitive to the levels of Hsp104; low levels of Hsp104 promote oligomer formation, oligomerization is prevented at high Hsp104 concentrations ${ }^{154}$, and loss of Hsp104 
eliminates prions ${ }^{155}$. To date, a homologous disaggregase has not been identified in metazoans.

\section{[H1] TREATING PROTEIN MISFOLDING DISORDERS}

Several different compounds have been used to fight protein aggregation disorders (Figure 3). While some reagents are designed to interfere with the aggregation process, others eliminate or even hyperstabilize the aggregates. Here we outline some approaches relevant to the treatment of PrDs and other protein aggregation disorders. A more comprehensive discussion of therapeutic principles can be found in a recent review ${ }^{156}$.

[H2] Inhibition of protein aggregation. The findings that p53 is a prionoid and that p53 aggregation plays a crucial role in some cancers ${ }^{157}$ opens up the potential for novel therapeutic strategies that specifically interfere with p53 aggregation (Figure 3A). The chaperone complex HSP90/HDAC6 has been shown to be upregulated in cancer cells and to stabilize p53 aggregates ${ }^{158}$. Interestingly, currently approved HSP90 inhibitors reduced tumor growth and extended survival time in mice expressing an aggregation-prone version of p53, while mice deficient for p53 were unaffected by HSP90 inhibitor treatment ${ }^{53}$. Furthermore, a peptide that binds the amyloid adhesive segment of p53 prevents p53 aggregation, restores p53 function, and induces cell death and tumor regression in mice ${ }^{159}$. The course of cancer treatment should thus not only be dependent on the identity of a mutated gene, but should also take the type of mutation into account. HSP90 inhibitors have also been applied to mouse models of neuronal PMDs. While effective in preventing $\alpha$-synuclein, $A \beta$, tau and Huntingtin aggregation and toxicity, long-term relief of disease symptoms has proven to be challenging ${ }^{144-147,160,161}$. Recently, HSP90 inhibition was observed to provide synaptic protection in a mouse AD model ${ }^{160}$, suggesting that chaperone modulation might indeed be a promising therapeutic approach for neuronal PMDs in the future.

[H2] Depletion of substrates with anti-prions. An orthogonal approach to interfere with protein aggregation is the design of anti-prions. Anti-prions are innocuous PrP aggregates that, upon injection, can compete with prions for the same substrate, $\mathrm{PrP}^{\mathrm{C}}$, thereby reducing prion replication (Figure 3B). Page | 17 
1 Anti-prions delay the onset of clinical symptoms in prion-injected hamsters and prevent disease

2 manifestation in animals exposed to low quantities of prions. Interestingly, a single dose of anti-prion

3 reduced prion infectivity by $99 \%$, making anti-prions an interesting candidate for therapy ${ }^{162}$. Most

4 therapeutics are rapidly metabolized, consumed or degraded and therefore need to be administered on

5 a regular basis. By contrast, anti-prions self-replicate and are therefore self-sustaining until their source,

$6 \quad \operatorname{PrP}^{\mathrm{C}}$, is depleted. Anti-prions are therefore also tantalizing therapeutics for other neurodegenerative

7 PMDs. While it is possible that the depletion of the substrate might cause deleterious effects, these may

8 be limited and tolerable. For instance, mice lacking $\operatorname{PrP}^{\mathrm{C}}$ suffer from relatively mild phenotypes ${ }^{23}$, and

9 mice without $\alpha$-synuclein display no gross morphological or behavioral abnormalities ${ }^{163}$. However,

10 mice lacking $\mathrm{A} \beta$ showed impaired neuronal function ${ }^{164}$. Thus, the pros and cons of substrate depletion

11 versus inhibition of aggregation will be different for each PMD and will require careful consideration.

[H2] Stabilization of protein aggregates. The most important stage in the replicative cycle of a prion is arguably the fragmentation of an aggregate into two or more propagons, as this is the process by which prions multiply. Indeed, theoretical models have predicted, and studies in experimental models have validated, that the frangibility of amyloid fibrils is the most important parameter governing the rate of replication of prions ${ }^{6}$. Thus, any therapeutic strategy based on 'beta sheet breakers ${ }^{165}$, which are homologous peptides that are unable to adopt higher-order structures, might increase rather than reduce the number of prions. A promising alternative approach is to instead hyperstabilize aggregates to prevent their fragmentation and replication (Figure 3C). Luminescent conjugated polythiophenes (LCPs) bind to a variety of amyloids ${ }^{166}$, and have also been shown to bind and stabilize prions ${ }^{167}$. LCPs optimized for prion binding were efficacious against multiple prions strains ${ }^{168}$ and could extend the lifespan of prion-exposed mice by up to $80 \%{ }^{169}$. LCPs are well tolerated in mice and can cross the blood-brain-barrier, which, together with their high affinity for many amyloids, make them interesting candidates for therapeutic development.

27 [H2] Antibodies. Antibodies are currently considered to be promising therapeutics for the treatment of Page | 18 
1 protein aggregation disorders. By specifically targeting complex and often conformation-dependent

2 antigens, antibodies are thought to have fewer off-target effects than traditional small-molecule

3 therapeutics. An increasing number of human-derived antibodies are entering clinical trials for various

4 diseases, and are thought to have a better safety profile than their "humanized" counterparts ${ }^{170}$.

5 In the case of protein aggregation disorders, it is conceivable that antibodies exert protective effects

6 through multiple different mechanisms (Figure 3D). For instance, antibodies can bind to monomeric or

7 aggregated proteins thereby making the substrate unavailable for conversion into aggregates ${ }^{171}$ and/or sterically interfering with the aggregation process itself. Certain prion antibodies have been suggested to act by a different mechanism, which involves targeting a part of the prion protein that is required for exerting toxicity; in this case, antibodies engaging the flexible tail can counteract prion-induced toxicity. While the antibody does not reduce infectivity, it interferes with downstream events triggered by prions and prevents them from inducing neurodegeneration ${ }^{79}$. Finally, antibodies can specifically bind to and neutralize aggregates, resulting in more efficient clearance of toxic species from affected tissues, for instance by phagocytic cells ${ }^{172-174}$. Indeed, research into AD therapeutics focuses on antibodies that specifically detect and eliminate amyloid deposits. One promising AD drug currently undergoing clinical trials, aducanumab, is an antibody isolated from a human centenarian who showed no signs of cognitive impairment. It was speculated that this donor individual may have developed antibodies against aggregated $\mathrm{A} \beta$, which safeguarded against dementia. Aducanumab targets and reduces aggregated $A \beta$ in a dose- and time-dependent manner similarly to previously investigated antibodies but, in contrast to other antibodies, it appears to slow the rate of clinical decline ${ }^{175}$. However, this study must be viewed in context: there is currently no population-based evidence that spontaneous immunity against $\mathrm{A} \beta$ exists in humans and is protective against $\mathrm{AD}$. Furthermore, as stated above, certain PrP antibodies are toxic, suggesting that caution should be exercised in clinical trials of immunotherapies. Nonetheless, in our view, the prospects of immunotherapy for the treatment of neurodegenerative diseases remain promising.

It is also important to note that a reduction of $A \beta$ aggregates does not necessarily impact the clinical progression of $\mathrm{AD}$, as powerfully demonstrated by the failure of numerous clinical trials despite 
1 convincing pharmacodynamics ${ }^{176}$. Furthermore, the deposition of $A \beta$ aggregates has been observed in

2 individuals without dementia ${ }^{177}$ and is thought to occur decades before the onset of clinical symptoms

3 of $\mathrm{AD}$, which seems to correlate with neurodegeneration rather than amyloid deposition ${ }^{178}$. One likely

4 explanation for the failure of many AD trials might therefore lie within the trial design and not the

5 efficacy of the tested compound. Many patients display clinical symptoms at the time of enrolment, a

6 stage where amyloid deposits might have already induced irreversible toxicity. With the development

7 of novel technologies and the identification of new biomarkers, the early diagnosis and enrolment of

8 preclinical $\mathrm{AD}$ patients has become possible, and will hopefully yield promising outcomes for upcoming clinical trials. The difficulty of correctly diagnosing $\mathrm{AD}$, combined with the high prevalence of the disease (more than $9 \%$ of individuals older than 65 ), raises the question whether AD therapeutics should be administered prophylactically in the future.

\section{[H1] CONClusions AND FUture Perspectives}

To date, fortunately neither AD nor PD nor any other protein aggregation disease are known to have caused a human epidemic such as kuru and vCJD. However, the prevalence of these diseases is high and their causes are still largely unknown, which complicates the detection of infectious aggregates that can spread between individuals. Nevertheless, from a medical perspective, PrDs currently still stand out as infectious diseases with many similarities to viral encephalopathies; they are therefore profoundly distinct from all other neurodegenerative diseases despite their similarities in molecular pathogenesis. Using its original definition as an infectious protein-, no protein aggregate other than $\mathrm{PrP}^{\mathrm{Sc}}$ can currently be called a prion. It is possible that some of the proteins that currently qualify as prionoids - in particular, the aggregated forms of synuclein ${ }^{179}$ and AA amyloid ${ }^{180}$ - may have to be reclassified as true prions if they are shown to be infectious.

Several orthogonal therapeutic strategies have been undertaken to combat protein aggregation and its corresponding diseases. Many of these therapies have shown promise in vitro and in mice, but it remains to be determined if these results hold up in human studies. Indeed, clinical trials for protein aggregation disorders have, with few exceptions, yielded vastly disappointing results ${ }^{176}$. However, our knowledge 
of these diseases has increased tremendously over the past decades. Research on PrDs has historically led the field of PMDs and the mouse model for PrD has been shown to recapitulate transcriptome-wide changes in human patients more faithfully than other neurodegenerative disease models ${ }^{181}$. Studies on prions are therefore likely to continue to drive our understanding of aggregation-induced toxicity. Several similarities between different protein aggregates have been identified, and different aggregates seem to exert toxicity, at least partly, by the same pathways. All of which suggests that insights gained on one of these disorders may be valid for other protein aggregation disorders. These findings, combined with the development of novel technologies, may allow the development of effective treatments for PMDs in the future.

\section{References}

1. Brown, P., Cathala, F., Castaigne, P. \& GAJDUSEK, D. C. Creutzfeldt-Jakob disease: clinical analysis of a consecutive series of 230 neuropathologically verified cases. Ann. Neurol. 20, 597-602 (1986).

2. Prusiner, S. B. Novel proteinaceous infectious particles cause scrapie. Science 216, 136-144 (1982).

This paper contains the first use of the term prion to describe the revolutionary concept of protein mediated transmissibility.

3. Bolton, D. C., McKinley, M. P. \& Prusiner, S. B. Identification of a protein that purifies with the scrapie prion. Science 218, 1309-1311 (1982).

This study demonstrated that prions contain an aggregated form of a cellular protein.

4. Büeler, H. et al. Mice devoid of PrP are resistant to scrapie. Cell 73, 1339-1347 (1993).

This paper provided confirmation that $\mathrm{PrP}^{\mathrm{C}}$ is required for prion propagation and disease manifestation.

5. Jarrett, J. T. \& Lansbury, P. T. Seeding 'one-dimensional crystallization' of amyloid: a pathogenic mechanism in Alzheimer's disease and scrapie? Cell 73, 1055-1058 (1993).

6. Knowles, T. P. J. et al. An analytical solution to the kinetics of breakable filament assembly. Science 326, 1533-1537 (2009).

This analytical approach describes how fragmentation-nucleation cycles contribute to aggregate propagation.

7. Cox, B., Ness, F. \& Tuite, M. Analysis of the generation and segregation of propagons: entities that propagate the [PSI+] prion in yeast. Genetics 165, 23-33 (2003).

8. Aguzzi, A. \& Lakkaraju, A. K. K. Cell Biology of Prions and Prionoids: A Status Report. Trends Cell Biol. 26, 40-51 (2016).

9. Saborio, G. P., Permanne, B. \& Soto, C. Sensitive detection of pathological prion protein by cyclic amplification of protein misfolding. Nature 411, 810-813 (2001).

10. Sailer, A., Büeler, H., Fischer, M., Aguzzi, A. \& Weissmann, C. No propagation of prions in mice devoid of PrP. Cell 77, 967-968 (1994).

11. Brandner, S. et al. Normal host prion protein necessary for scrapie-induced neurotoxicity. Nature 379, 339-343 (1996).

This paper demonstrated that aggregation and aggregation-induced toxicity can be uncoupled by chronically exposing PrP-deficient mice to prions.

12. Hu, P. P. et al. Role of Prion Replication in the Strain-dependent Brain Regional Distribution 
of Prions. J. Biol. Chem. 291, 12880-12887 (2016).

13. Glatzel, M., Abela, E., Maissen, M. \& Aguzzi, A. Extraneural pathologic prion protein in sporadic Creutzfeldt-Jakob disease. N. Engl. J. Med. 349, 1812-1820 (2003).

14. Aguzzi, A. Cell biology: Beyond the prion principle. Nature 459, 924-925 (2009).

This paper introduced the term prionoid to describe aggregates that can spread between cells but for which transmissibility between individuals has not yet been demonstrated.

15. Aguzzi, A. \& Rajendran, L. The transcellular spread of cytosolic amyloids, prions, and prionoids. Neuron 64, 783-790 (2009).

16. Bruce, M. E. et al. Transmissions to mice indicate that 'new variant' CJD is caused by the BSE agent. Nature 389, 498-501 (1997).

17. Wells, G. A. et al. A novel progressive spongiform encephalopathy in cattle. Vet. Rec. 121, 419-420 (1987).

18. Williams, E. S. \& Young, S. Chronic wasting disease of captive mule deer: a spongiform encephalopathy. J. Wildl. Dis. 16, 89-98 (1980).

19. Aguzzi, A., Heikenwalder, M. \& Polymenidou, M. Insights into prion strains and neurotoxicity. Nat. Rev. Mol. Cell Biol. 8, 552-561 (2007).

20. Kretzschmar, H. A. et al. Molecular cloning of a human prion protein cDNA. DNA 5, 315324 (1986).

21. Riek, R. et al. NMR structure of the mouse prion protein domain $\operatorname{Pr} \mathrm{P}(121-231)$. Nature 382, 180-182 (1996).

22. Wulf, M.-A., Senatore, A. \& Aguzzi, A. The biological function of the cellular prion protein: an update. BMC Biol. 15, 34 (2017).

23. Nuvolone, M. et al. Strictly co-isogenic C57BL/6J-Prnp-/- mice: A rigorous resource for prion science. J. Exp. Med. 213, 313-327 (2016).

24. Nuvolone, M. et al. SIRP $\alpha$ polymorphisms, but not the prion protein, control phagocytosis of apoptotic cells. J. Exp. Med. 210, 2539-2552 (2013).

25. Bremer, J. et al. Axonal prion protein is required for peripheral myelin maintenance. Nat. Neurosci. 13, 310-318 (2010).

26. Küffer, A. et al. The prion protein is an agonistic ligand of the $\mathrm{G}$ protein-coupled receptor Adgrg6. Nature 536, 464-468 (2016).

27. Hsiao, K. et al. Linkage of a prion protein missense variant to Gerstmann-Sträussler syndrome. Nature 338, 342-345 (1989).

28. Medori, R. et al. Fatal familial insomnia, a prion disease with a mutation at codon 178 of the prion protein gene. N. Engl. J. Med. 326, 444-449 (1992).

29. Kretzschmar, H. A., Neumann, M. \& Stavrou, D. Codon 178 mutation of the human prion protein gene in a German family (Backer family): sequencing data from 72-year-old celloidin-embedded brain tissue. Acta Neuropathol. 89, 96-98 (1995).

30. Apetri, A. C., Vanik, D. L. \& Surewicz, W. K. Polymorphism at residue 129 modulates the conformational conversion of the D178 N variant of human prion protein 90-231.

Biochemistry 44, 15880-15888 (2005).

31. Hsiao, K. et al. Mutation of the prion protein in Libyan Jews with Creutzfeldt-Jakob disease. N. Engl. J. Med. 324, 1091-1097 (1991).

32. Pocchiari, M. et al. A new point mutation of the prion protein gene in Creutzfeldt-Jakob disease. Ann. Neurol. 34, 802-807 (1993).

33. Capellari, S., Strammiello, R., Saverioni, D., Kretzschmar, H. \& Parchi, P. Genetic Creutzfeldt-Jakob disease and fatal familial insomnia: insights into phenotypic variability and disease pathogenesis. Acta Neuropathol. 121, 21-37 (2011).

34. Parchi, P. et al. Molecular basis of phenotypic variability in sporadic Creutzfeldt-Jakob disease. Ann. Neurol. 39, 767-778 (1996).

35. Palmer, M. S., Dryden, A. J., Hughes, J. T. \& Collinge, J. Homozygous prion protein genotype predisposes to sporadic Creutzfeldt-Jakob disease. Nature 352, 340-342 (1991).

36. Nurmi, M. H. et al. The normal population distribution of PRNP codon 129 polymorphism. Acta Neurol. Scand. 108, 374-378 (2003).

37. Pocchiari, M. et al. Predictors of survival in sporadic Creutzfeldt-Jakob disease and other 
human transmissible spongiform encephalopathies. Brain 127, 2348-2359 (2004).

38. Mok, T. et al. Variant Creutzfeldt-Jakob Disease in a Patient with Heterozygosity at PRNP Codon 129. N. Engl. J. Med. 376, 292-294 (2017).

39. Llewelyn, C. A. et al. Possible transmission of variant Creutzfeldt-Jakob disease by blood transfusion. Lancet 363, 417-421 (2004).

40. Wroe, S. J. et al. Clinical presentation and pre-mortem diagnosis of variant CreutzfeldtJakob disease associated with blood transfusion: a case report. Lancet 368, 2061-2067 (2006).

41. Peden, A. H., Head, M. W., Ritchie, D. L., Bell, J. E. \& Ironside, J. W. Preclinical vCJD after blood transfusion in a PRNP codon 129 heterozygous patient. Lancet 364, 527-529 (2004).

42. Mead, S. et al. A novel protective prion protein variant that colocalizes with kuru exposure. N. Engl. J. Med. 361, 2056-2065 (2009).

43. Shibuya, S., Higuchi, J., Shin, R. W., Tateishi, J. \& Kitamoto, T. Protective prion protein polymorphisms against sporadic Creutzfeldt-Jakob disease. Lancet 351, 419 (1998).

44. Asante, E. A. et al. A naturally occurring variant of the human prion protein completely prevents prion disease. Nature 522, 478-481 (2015).

45. Mead, S. et al. Genetic risk factors for variant Creutzfeldt-Jakob disease: a genome-wide association study. Lancet Neurol 8, 57-66 (2009).

46. Mead, S. et al. Genome-wide association study in multiple human prion diseases suggests genetic risk factors additional to PRNP. Hum. Mol. Genet. 21, 1897-1906 (2012).

47. Sanchez-Juan, P. et al. A genome wide association study links glutamate receptor pathway to sporadic Creutzfeldt-Jakob disease risk. PLoS ONE 10, e0123654 (2014).

48. Minikel, E. V. et al. Quantifying prion disease penetrance using large population control cohorts. Sci Transl Med 8, 322 ra9 (2016).

49. $\mathrm{Xu}, \mathrm{J}$. et al. Gain of function of mutant $\mathrm{p} 53$ by coaggregation with multiple tumor suppressors. Nat. Chem. Biol. 7, 285-295 (2011).

50. Levy, C. B. et al. Co-localization of mutant p53 and amyloid-like protein aggregates in breast tumors. Int. J. Biochem. Cell Biol. 43, 60-64 (2011).

51. Forget, K. J., Tremblay, G. \& Roucou, X. p53 Aggregates penetrate cells and induce the coaggregation of intracellular p53. PLoS ONE 8, e69242 (2013).

52. Ghosh, S. et al. p53 amyloid formation leading to its loss of function: implications in cancer pathogenesis. Cell Death Differ. 24, 1784-1798 (2017).

53. Alexandrova, E. M. et al. Improving survival by exploiting tumour dependence on stabilized mutant p53 for treatment. Nature 523, 352-356 (2015).

54. Mukherjee, A. et al. Induction of IAPP amyloid deposition and associated diabetic abnormalities by a prion-like mechanism. J. Exp. Med. 214, 2591-2610 (2017).

55. Murakami, T., Ishiguro, N. \& Higuchi, K. Transmission of systemic AA amyloidosis in animals. Vet. Pathol. 51, 363-371 (2014).

56. Watts, J. C. et al. Transmission of multiple system atrophy prions to transgenic mice. Proc. Natl. Acad. Sci. U.S.A. 110, 19555-19560 (2013).

This study demonstrated that $\alpha$-synuclein aggregates are transmissible to mice expressing a human aggregation-prone form of $\alpha$-synuclein.

57. Prusiner, S. B. et al. Evidence for $\alpha$-synuclein prions causing multiple system atrophy in humans with parkinsonism. Proc. Natl. Acad. Sci. U.S.A. 112, E5308-17 (2015).

58. Sigurdson, C. J. et al. A molecular switch controls interspecies prion disease transmission in mice. J. Clin. Invest. 120, 2590-2599 (2010).

59. Sacino, A. N. et al. Non-prion-type transmission in A53T $\alpha$-synuclein transgenic mice: a normal component of spinal homogenates from naïve non-transgenic mice induces robust $\alpha$ synuclein pathology. Acta Neuropathol. 131, 151-154 (2016).

60. Kurowska, Z. et al. Signs of degeneration in 12-22-year old grafts of mesencephalic dopamine neurons in patients with Parkinson's disease. J Parkinsons Dis 1, 83-92 (2011).

61. Kordower, J. H., Chu, Y., Hauser, R. A., Freeman, T. B. \& Olanow, C. W. Lewy body-like pathology in long-term embryonic nigral transplants in Parkinson's disease. Nat. Med. 14, 
504-506 (2008).

62. Kordower, J. H., Chu, Y., Hauser, R. A., Olanow, C. W. \& Freeman, T. B. Transplanted dopaminergic neurons develop PD pathologic changes: a second case report. Mov. Disord. 23, 2303-2306 (2008).

63. Li, W. et al. Extensive graft-derived dopaminergic innervation is maintained 24 years after transplantation in the degenerating parkinsonian brain. Proc. Natl. Acad. Sci. U.S.A. 113, 6544-6549 (2016).

64. Li, J.-Y. et al. Lewy bodies in grafted neurons in subjects with Parkinson's disease suggest host-to-graft disease propagation. Nat. Med. 14, 501-503 (2008).

65. Thal, D. R., Rüb, U., Orantes, M. \& Braak, H. Phases of A beta-deposition in the human brain and its relevance for the development of AD. Neurology 58, 1791-1800 (2002).

66. Meyer-Luehmann, M. et al. Exogenous induction of cerebral beta-amyloidogenesis is governed by agent and host. Science 313, 1781-1784 (2006).

67. Stöhr, J. et al. Purified and synthetic Alzheimer's amyloid beta (A $\beta)$ prions. Proc. Natl. Acad. Sci. U.S.A. 109, 11025-11030 (2012).

68. Jaunmuktane, Z. et al. Evidence for human transmission of amyloid- $\beta$ pathology and cerebral amyloid angiopathy. Nature 525, 247-250 (2015).

69. Ritchie, D. L. et al. Amyloid- $\beta$ accumulation in the CNS in human growth hormone recipients in the UK. Acta Neuropathol. 134, 221-240 (2017).

70. Frontzek, K., Lutz, M. I., Aguzzi, A., Kovacs, G. G. \& Budka, H. Amyloid- $\beta$ pathology and cerebral amyloid angiopathy are frequent in iatrogenic Creutzfeldt-Jakob disease after dural grafting. Swiss Med Wkly 146, w14287 (2016).

71. Arnold, S. E. et al. Comparative survey of the topographical distribution of signature molecular lesions in major neurodegenerative diseases. J. Comp. Neurol. 521, 4339-4355 (2013).

72. Audouard, E. et al. High-Molecular-Weight Paired Helical Filaments from Alzheimer Brain Induces Seeding of Wild-Type Mouse Tau into an Argyrophilic 4R Tau Pathology in Vivo. Am. J. Pathol. 186, 2709-2722 (2016).

73. Duyckaerts, C. et al. Neuropathology of iatrogenic Creutzfeldt-Jakob disease and immunoassay of French cadaver-sourced growth hormone batches suggest possible transmission of tauopathy and long incubation periods for the transmission of Abeta pathology. Acta Neuropathol. (2017). doi:10.1007/s00401-017-1791-x

74. Malinovska, L., Kroschwald, S. \& Alberti, S. Protein disorder, prion propensities, and selforganizing macromolecular collectives. Biochim. Biophys. Acta 1834, 918-931 (2013).

75. Hyman, A. A., Weber, C. A. \& Jülicher, F. Liquid-liquid phase separation in biology. Annu. Rev. Cell Dev. Biol. 30, 39-58 (2014).

76. Sonati, T. et al. The toxicity of antiprion antibodies is mediated by the flexible tail of the prion protein. Nature 501, 102-106 (2013).

This study demonstrated that antibodies can be protective or toxic, depending on the recognized epitope.

77. Heppner, F. L. et al. Prevention of scrapie pathogenesis by transgenic expression of antiprion protein antibodies. Science 294, 178-182 (2001).

This paper introduced the novel concept that prion disease pathogenesis can be inhibited by protective PrP antibodies.

78. Polymenidou, M. et al. The POM monoclonals: a comprehensive set of antibodies to nonoverlapping prion protein epitopes. PLoS ONE 3, e3872 (2008).

79. Herrmann, U. S. et al. Prion infections and anti-PrP antibodies trigger converging neurotoxic pathways. PLoS Pathog. 11, e1004662 (2015).

80. Falsig, J. et al. Prion pathogenesis is faithfully reproduced in cerebellar organotypic slice cultures. PLoS Pathog. 8, e1002985 (2012).

81. Frontzek, K. et al. Neurotoxic Antibodies against the Prion Protein Do Not Trigger Prion Replication. PLoS ONE 11, e0163601 (2016).

82. Yim, Y.-I. et al. The multivesicular body is the major internal site of prion conversion. $J$. Cell. Sci. 128, 1434-1443 (2015). 
83. Vella, L. J., Hill, A. F. \& Cheng, L. Focus on Extracellular Vesicles: Exosomes and Their Role in Protein Trafficking and Biomarker Potential in Alzheimer's and Parkinson's Disease. Int J Mol Sci 17, 173 (2016).

84. Gousset, K. et al. Prions hijack tunnelling nanotubes for intercellular spread. Nat. Cell Biol. 11, 328-336 (2009).

85. Senatore, A. et al. Mutant PrP suppresses glutamatergic neurotransmission in cerebellar granule neurons by impairing membrane delivery of VGCC $\alpha(2) \delta$-1 Subunit. Neuron 74, 300-313 (2012).

86. Rodríguez, A. et al. Metabotropic glutamate receptor/phospholipase C pathway: a vulnerable target to Creutzfeldt-Jakob disease in the cerebral cortex. Neuroscience 131, 825-832 (2005).

87. Rodríguez, A. et al. Group I mGluR signaling in BSE-infected bovine-PrP transgenic mice. Neurosci. Lett. 410, 115-120 (2006).

88. Goniotaki, D. et al. Inhibition of group-I metabotropic glutamate receptors protects against prion toxicity. PLoS Pathog. 13, e1006733 (2017).

89. Khosravani, H. et al. Prion protein attenuates excitotoxicity by inhibiting NMDA receptors. J. Gen. Physiol. 131, i5 (2008).

90. Laurén, J., Gimbel, D. A., Nygaard, H. B., Gilbert, J. W. \& Strittmatter, S. M. Cellular prion protein mediates impairment of synaptic plasticity by amyloid-beta oligomers. Nature 457, 1128-1132 (2009).

91. Gimbel, D. A. et al. Memory impairment in transgenic Alzheimer mice requires cellular prion protein. J. Neurosci. 30, 6367-6374 (2010).

92. Haas, L. T., Kostylev, M. A. \& Strittmatter, S. M. Therapeutic molecules and endogenous ligands regulate the interaction between brain cellular prion protein (PrPC) and metabotropic glutamate receptor 5 (mGluR5). J. Biol. Chem. 289, 28460-28477 (2014).

93. Um, J. W. et al. Metabotropic glutamate receptor 5 is a coreceptor for Alzheimer a $\beta$ oligomer bound to cellular prion protein. Neuron 79, 887-902 (2013).

94. Um, J. W. et al. Alzheimer amyloid- $\beta$ oligomer bound to postsynaptic prion protein activates Fyn to impair neurons. Nat. Neurosci. 15, 1227-1235 (2012).

95. $\mathrm{Hu}, \mathrm{N}$.-W. et al. mGlu5 receptors and cellular prion protein mediate amyloid- $\beta$-facilitated synaptic long-term depression in vivo. Nat Commun 5, 3374 (2014).

96. Ostapchenko, V. G. et al. Increased prion protein processing and expression of metabotropic glutamate receptor 1 in a mouse model of Alzheimer's disease. J. Neurochem. 127, 415-425 (2013).

97. Renner, M. et al. Deleterious effects of amyloid beta oligomers acting as an extracellular scaffold for mGluR5. Neuron 66, 739-754 (2010).

98. Hamilton, A., Esseltine, J. L., DeVries, R. A., Cregan, S. P. \& Ferguson, S. S. G. Metabotropic glutamate receptor 5 knockout reduces cognitive impairment and pathogenesis in a mouse model of Alzheimer's disease. Mol Brain 7, 40 (2014).

99. Balducci, C. et al. Synthetic amyloid-beta oligomers impair long-term memory independently of cellular prion protein. Proc. Natl. Acad. Sci. U.S.A. 107, 2295-2300 (2010).

100. Kessels, H. W., Nguyen, L. N., Nabavi, S. \& Malinow, R. The prion protein as a receptor for amyloid-beta. Nature 466, E3-4- discussion E4-5 (2010).

101. Calella, A. M. et al. Prion protein and Abeta-related synaptic toxicity impairment. EMBO Mol Med 2, 306-314 (2010).

102. Cissé, M. et al. Ablation of cellular prion protein does not ameliorate abnormal neural network activity or cognitive dysfunction in the J20 line of human amyloid precursor protein transgenic mice. J. Neurosci. 31, 10427-10431 (2011).

103. Aulić, S. et al. $\alpha$-Synuclein Amyloids Hijack Prion Protein to Gain Cell Entry, Facilitate Cell-to-Cell Spreading and Block Prion Replication. Sci Rep 7, 10050 (2017).

104. Ferreira, D. G. et al. $\alpha$-synuclein interacts with $\operatorname{PrP}(\mathrm{C})$ to induce cognitive impairment through mGluR5 and NMDAR2B. Nat. Neurosci. 20, 1569-1579 (2017).

105. Diógenes, M. J. et al. Extracellular alpha-synuclein oligomers modulate synaptic 
transmission and impair LTP via NMDA-receptor activation. J. Neurosci. 32, 11750-11762 (2012).

106. Parizek, P. et al. Similar turnover and shedding of the cellular prion protein in primary lymphoid and neuronal cells. J. Biol. Chem. 276, 44627-44632 (2001).

107. Yedidia, Y., Horonchik, L., Tzaban, S., Yanai, A. \& Taraboulos, A. Proteasomes and ubiquitin are involved in the turnover of the wild-type prion protein. EMBO J. 20, 53835391 (2001).

108. Ma, J. \& Lindquist, S. Conversion of PrP to a self-perpetuating PrPSc-like conformation in the cytosol. Science 298, 1785-1788 (2002).

109. Stewart, R. S., Drisaldi, B. \& Harris, D. A. A transmembrane form of the prion protein contains an uncleaved signal peptide and is retained in the endoplasmic Reticulum. Mol. Biol. Cell 12, 881-889 (2001).

110. Ma, J. \& Lindquist, S. Wild-type PrP and a mutant associated with prion disease are subject to retrograde transport and proteasome degradation. Proc. Natl. Acad. Sci. U.S.A. 98, 1495514960 (2001).

111. Zanusso, G. et al. Proteasomal degradation and N-terminal protease resistance of the codon 145 mutant prion protein. J. Biol. Chem. 274, 23396-23404 (1999).

112. Jin, T. et al. The chaperone protein BiP binds to a mutant prion protein and mediates its degradation by the proteasome. J. Biol. Chem. 275, 38699-38704 (2000).

113. Drisaldi, B. et al. Mutant PrP is delayed in its exit from the endoplasmic reticulum, but neither wild-type nor mutant PrP undergoes retrotranslocation prior to proteasomal degradation. J. Biol. Chem. 278, 21732-21743 (2003).

114. Kristiansen, M. et al. Disease-associated prion protein oligomers inhibit the $26 \mathrm{~S}$ proteasome. Mol. Cell 26, 175-188 (2007).

115. Kristiansen, M. et al. Disease-related prion protein forms aggresomes in neuronal cells leading to caspase activation and apoptosis. J. Biol. Chem. 280, 38851-38861 (2005).

116. Deriziotis, P. et al. Misfolded PrP impairs the UPS by interaction with the 20S proteasome and inhibition of substrate entry. EMBO J. 30, 3065-3077 (2011).

117. Moreno, J. A. et al. Sustained translational repression by eIF2 $\alpha$-P mediates prion neurodegeneration. Nature 485, 507-511 (2012).

118. Abisambra, J. F. et al. Tau accumulation activates the unfolded protein response by impairing endoplasmic reticulum-associated degradation. J. Neurosci. 33, 9498-9507 (2013).

119. Atkin, J. D. et al. Endoplasmic reticulum stress and induction of the unfolded protein response in human sporadic amyotrophic lateral sclerosis. Neurobiol. Dis. 30, 400-407 (2008).

120. Devi, L. \& Ohno, M. PERK mediates eIF2 $\alpha$ phosphorylation responsible for BACE1 elevation, CREB dysfunction and neurodegeneration in a mouse model of Alzheimer's disease. Neurobiol. Aging 35, 2272-2281 (2014).

121. Saxena, S., Cabuy, E. \& Caroni, P. A role for motoneuron subtype-selective ER stress in disease manifestations of FALS mice. Nat. Neurosci. 12, 627-636 (2009).

122. Hoozemans, J. J. M. et al. Activation of the unfolded protein response in Parkinson's disease. Biochem. Biophys. Res. Commun. 354, 707-711 (2007).

123. Radford, H., Moreno, J. A., Verity, N., Halliday, M. \& Mallucci, G. R. PERK inhibition prevents tau-mediated neurodegeneration in a mouse model of frontotemporal dementia. Acta Neuropathol. 130, 633-642 (2015).

124. Horiuchi, M., Yamazaki, N., Ikeda, T., Ishiguro, N. \& Shinagawa, M. A cellular form of prion protein (PrPC) exists in many non-neuronal tissues of sheep. J. Gen. Virol. 76 ( Pt 10), 2583-2587 (1995).

125. Arai, H. et al. Expression patterns of beta-amyloid precursor protein (beta-APP) in neural and nonneural human tissues from Alzheimer's disease and control subjects. Ann. Neurol. 30, 686-693 (1991).

126. Gu, Y., Oyama, F. \& Ihara, Y. Tau is widely expressed in rat tissues. J. Neurochem. 67, 1235-1244 (1996). 
127. Klein, M. A. et al. A crucial role for B cells in neuroinvasive scrapie. Nature 390, 687-690 (1997).

128. Raeber, A. J. et al. Ectopic expression of prion protein (PrP) in T lymphocytes or hepatocytes of PrP knockout mice is insufficient to sustain prion replication. Proc. Natl. Acad. Sci. U.S.A. 96, 3987-3992 (1999).

129. Yang, W. \& Yu, S. Synucleinopathies: common features and hippocampal manifestations. Cell. Mol. Life Sci. 74, 1485-1501 (2017).

130. Ferrer, I., Casas, R. \& Rivera, R. Parvalbumin-immunoreactive cortical neurons in Creutzfeldt-Jakob disease. Ann. Neurol. 34, 864-866 (1993).

131. Guentchev, M., Groschup, M. H., Kordek, R., Liberski, P. P. \& Budka, H. Severe, early and selective loss of a subpopulation of GABAergic inhibitory neurons in experimental transmissible spongiform encephalopathies. Brain Pathol. 8, 615-623 (1998).

132. Guentchev, M., Wanschitz, J., Voigtländer, T., Flicker, H. \& Budka, H. Selective neuronal vulnerability in human prion diseases. Fatal familial insomnia differs from other types of prion diseases. Am. J. Pathol. 155, 1453-1457 (1999).

133. Sargent, D. et al. 'Prion-like' propagation of the synucleinopathy of M83 transgenic mice depends on the mouse genotype and type of inoculum. J. Neurochem. 143, 126-135 (2017).

134. Bu, X.-L. et al. Blood-derived amyloid- $\beta$ protein induces Alzheimer's disease pathologies. Mol. Psychiatry (2017). doi:10.1038/mp.2017.204

135. Glatzel, M., Heppner, F. L., Albers, K. M. \& Aguzzi, A. Sympathetic innervation of lymphoreticular organs is rate limiting for prion neuroinvasion. Neuron 31, 25-34 (2001).

136. Prinz, M. et al. Positioning of follicular dendritic cells within the spleen controls prion neuroinvasion. Nature 425, 957-962 (2003).

137. Hill, A. F. et al. The same prion strain causes VCJD and BSE. Nature 389, 448-50-526 (1997).

138. Saido, T. C. et al. Dominant and differential deposition of distinct beta-amyloid peptide species, A beta N3(pE), in senile plaques. Neuron 14, 457-466 (1995).

139. Schilling, S. et al. Glutaminyl cyclase inhibition attenuates pyroglutamate Abeta and Alzheimer's disease-like pathology. Nat. Med. 14, 1106-1111 (2008).

140. Castegna, A. et al. Proteomic identification of nitrated proteins in Alzheimer's disease brain. J. Neurochem. 85, 1394-1401 (2003).

141. Smith, M. A., Richey Harris, P. L., Sayre, L. M., Beckman, J. S. \& Perry, G. Widespread peroxynitrite-mediated damage in Alzheimer's disease. J. Neurosci. 17, 2653-2657 (1997).

142. Sweeney, P. et al. Protein misfolding in neurodegenerative diseases: implications and strategies. Transl Neurodegener 6, 6 (2017).

143. Steele, A. D. et al. Heat shock factor 1 regulates lifespan as distinct from disease onset in prion disease. Proc. Natl. Acad. Sci. U.S.A. 105, 13626-13631 (2008).

144. Baldo, B. et al. A screen for enhancers of clearance identifies huntingtin as a heat shock protein 90 (Hsp90) client protein. J. Biol. Chem. 287, 1406-1414 (2012).

145. Luo, W. et al. Roles of heat-shock protein 90 in maintaining and facilitating the neurodegenerative phenotype in tauopathies. Proc. Natl. Acad. Sci. U.S.A. 104, 9511-9516 (2007).

146. Labbadia, J. et al. Altered chromatin architecture underlies progressive impairment of the heat shock response in mouse models of Huntington disease. J. Clin. Invest. 121, 3306-3319 (2011).

147. Putcha, P. et al. Brain-permeable small-molecule inhibitors of Hsp90 prevent alphasynuclein oligomer formation and rescue alpha-synuclein-induced toxicity. J. Pharmacol. Exp. Ther. 332, 849-857 (2010).

148. Hetz, C., Russelakis-Carneiro, M., Maundrell, K., Castilla, J. \& Soto, C. Caspase-12 and endoplasmic reticulum stress mediate neurotoxicity of pathological prion protein. EMBO J. 22, 5435-5445 (2003).

149. Yoo, B. C. et al. Overexpressed protein disulfide isomerase in brains of patients with sporadic Creutzfeldt-Jakob disease. Neurosci. Lett. 334, 196-200 (2002).

150. Hoshino, T. et al. Endoplasmic reticulum chaperones inhibit the production of amyloid-beta 
peptides. Biochem. J. 402, 581-589 (2007).

151. Park, K.-W. et al. The Endoplasmic Reticulum Chaperone GRP78/BiP Modulates Prion Propagation in vitro and in vivo. Sci Rep 7, 44723 (2017).

152. Hetz, C. et al. The disulfide isomerase Grp58 is a protective factor against prion neurotoxicity. J. Neurosci. 25, 2793-2802 (2005).

153. Glover, J. R. \& Lindquist, S. Hsp104, Hsp70, and Hsp40: a novel chaperone system that rescues previously aggregated proteins. Cell 94, 73-82 (1998).

154. Shorter, J. \& Lindquist, S. Hsp104 catalyzes formation and elimination of self-replicating Sup35 prion conformers. Science 304, 1793-1797 (2004).

155. Chernoff, Y. O., Lindquist, S. L., Ono, B., Inge-Vechtomov, S. G. \& Liebman, S. W. Role of the chaperone protein Hsp104 in propagation of the yeast prion-like factor [psi+]. Science 268, 880-884 (1995).

156. Aguzzi, A., Lakkaraju, A. K. K. \& Frontzek, K. Toward Therapy of Human Prion Diseases. Annu. Rev. Pharmacol. Toxicol. (2017). doi:10.1146/annurev-pharmtox-010617-052745

157. Silva, J. L., De Moura Gallo, C. V., Costa, D. C. F. \& Rangel, L. P. Prion-like aggregation of mutant p53 in cancer. Trends Biochem. Sci. 39, 260-267 (2014).

158. Whitesell, L. \& Lindquist, S. L. HSP90 and the chaperoning of cancer. Nat. Rev. Cancer 5, 761-772 (2005).

159. Soragni, A. et al. A Designed Inhibitor of p53 Aggregation Rescues p53 Tumor Suppression in Ovarian Carcinomas. Cancer Cell 29, 90-103 (2016).

160. Wang, B. et al. A CNS-permeable Hsp90 inhibitor rescues synaptic dysfunction and memory loss in APP-overexpressing Alzheimer's mouse model via an HSF1-mediated mechanism. Mol. Psychiatry 22, 990-1001 (2017).

161. Ansar, S. et al. A non-toxic Hsp90 inhibitor protects neurons from Abeta-induced toxicity. Bioorg. Med. Chem. Lett. 17, 1984-1990 (2007).

162. Diaz-Espinoza, R. et al. Treatment with a non-toxic, self-replicating anti-prion delays or prevents prion disease in vivo. Mol. Psychiatry (2017). doi:10.1038/mp.2017.84

163. Abeliovich, A. et al. Mice lacking alpha-synuclein display functional deficits in the nigrostriatal dopamine system. Neuron 25, 239-252 (2000).

164. Zheng, H. et al. beta-Amyloid precursor protein-deficient mice show reactive gliosis and decreased locomotor activity. Cell 81, 525-531 (1995).

165. Soto, C. et al. Reversion of prion protein conformational changes by synthetic beta-sheet breaker peptides. Lancet 355, 192-197 (2000).

166. Nilsson, K. P. R. et al. Structural typing of systemic amyloidoses by luminescent-conjugated polymer spectroscopy. Am. J. Pathol. 176, 563-574 (2010).

167. Margalith, I. et al. Polythiophenes inhibit prion propagation by stabilizing prion protein (PrP) aggregates. J. Biol. Chem. 287, 18872-18887 (2012).

168. Sigurdson, C. J. et al. Prion strain discrimination using luminescent conjugated polymers. Nat. Methods 4, 1023-1030 (2007).

169. Herrmann, U. S. et al. Structure-based drug design identifies polythiophenes as antiprion compounds. Sci Transl Med 7, 299ra123 (2015).

170. Frenzel, A., Schirrmann, T. \& Hust, M. Phage display-derived human antibodies in clinical development and therapy. MAbs 8, 1177-1194 (2016).

171. Polymenidou, M. et al. Humoral immune response to native eukaryotic prion protein correlates with anti-prion protection. Proc. Natl. Acad. Sci. U.S.A. 101 Suppl 2, 1467014676 (2004).

172. Falsig, J. \& Aguzzi, A. The prion organotypic slice culture assay--POSCA. Nat Protoc 3, 555-562 (2008).

173. Zhu, C. et al. A neuroprotective role for microglia in prion diseases. J. Exp. Med. 213, 10471059 (2016).

174. Kranich, J. et al. Engulfment of cerebral apoptotic bodies controls the course of prion disease in a mouse strain-dependent manner. J. Exp. Med. 207, 2271-2281 (2010).

175. Sevigny, J. et al. The antibody aducanumab reduces $A \beta$ plaques in Alzheimer's disease. Nature 537, 50-56 (2016). 
This paper describes the first therapeutic, the human antibody aducanumab, shown to affect the cognitive decline in $A D$ patients.

176. Cummings, J. L., Morstorf, T. \& Zhong, K. Alzheimer's disease drug-development pipeline: few candidates, frequent failures. Alzheimers Res Ther 6, 37 (2014).

177. Price, J. L. \& Morris, J. C. Tangles and plaques in nondemented aging and 'preclinical' Alzheimer's disease. Ann. Neurol. 45, 358-368 (1999).

178. Jack, C. R. et al. Serial PIB and MRI in normal, mild cognitive impairment and Alzheimer's disease: implications for sequence of pathological events in Alzheimer's disease. Brain 132, 1355-1365 (2009).

179. Luk, K. C. et al. Pathological $\alpha$-synuclein transmission initiates Parkinson-like neurodegeneration in nontransgenic mice. Science 338, 949-953 (2012).

180. Lundmark, K. et al. Transmissibility of systemic amyloidosis by a prion-like mechanism. Proc. Natl. Acad. Sci. U.S.A. 99, 6979-6984 (2002).

181. Burns, T. C., Li, M. D., Mehta, S., Awad, A. J. \& Morgan, A. A. Mouse models rarely mimic the transcriptome of human neurodegenerative diseases: A systematic bioinformaticsbased critique of preclinical models. Eur. J. Pharmacol. 759, 101-117 (2015).

182. Zanusso, G., Monaco, S., Pocchiari, M. \& Caughey, B. Advanced tests for early and accurate diagnosis of Creutzfeldt-Jakob disease. Nat Rev Neurol 12, 325-333 (2016).

183. Edgeworth, J. A. et al. Detection of prion infection in variant Creutzfeldt-Jakob disease: a blood-based assay. Lancet 377, 487-493 (2011).

184. Jackson, G. S. et al. A highly specific blood test for vCJD. Blood 123, 452-453 (2014).

185. Saá, P., Castilla, J. \& Soto, C. Presymptomatic detection of prions in blood. Science 313, 9294 (2006).

186. Colby, D. W. et al. Prion detection by an amyloid seeding assay. Proc. Natl. Acad. Sci. U.S.A. 104, 20914-20919 (2007).

187. Atarashi, R. et al. Simplified ultrasensitive prion detection by recombinant PrP conversion with shaking. Nat. Methods 5, 211-212 (2008).

188. Atarashi, R. et al. Ultrasensitive human prion detection in cerebrospinal fluid by real-time quaking-induced conversion. Nat. Med. 17, 175-178 (2011).

189. Orrú, C. D. et al. Rapid and sensitive RT-QuIC detection of human Creutzfeldt-Jakob disease using cerebrospinal fluid. MBio 6, (2015).

190. Concha-Marambio, L. et al. Detection of prions in blood from patients with variant Creutzfeldt-Jakob disease. Sci Transl Med 8, 370ra183 (2016).

191. Bougard, D. et al. Detection of prions in the plasma of presymptomatic and symptomatic patients with variant Creutzfeldt-Jakob disease. Sci Transl Med 8, 370ra182 (2016).

192. Ito, D., Hatano, M. \& Suzuki, N. RNA binding proteins and the pathological cascade in ALS/FTD neurodegeneration. Sci Transl Med 9, (2017).

193. Jackson, W. S. Selective vulnerability to neurodegenerative disease: the curious case of Prion Protein. Dis Model Mech 7, 21-29 (2014).

194. Pettersen, E. F. et al. UCSF Chimera--a visualization system for exploratory research and analysis. J Comput Chem 25, 1605-1612 (2004).

195. Aguzzi, A., Baumann, F. \& Bremer, J. The prion's elusive reason for being. Annu. Rev. Neurosci. 31, 439-477 (2008).

\section{Acknowledgements}

C.S. is the recipient of a Marie Curie Individual Fellowship. A.A. is the recipient of an advanced grant of the European Research Council and grants from the Swiss National Research Foundation, the Clinical Research Priority Programs "Small RNAs" and "Human Hemato-Lymphatic Diseases" of the University of Zurich, and SystemsX.ch. Molecular graphics and analyses were performed with the 
1 UCSF Chimera package. Chimera is developed by the Resource for Biocomputing, Visualization, and

2 Informatics at the University of California, San Francisco (supported by NIGMS P41-GM103311).

4 Author contributions

5 Both authors contributed to researching, discussing, writing and editing this Review.

6

7 Competing interests

8 Adriano Aguzzi is a founder and director of Mabylon Inc., a company devoted to the development of 9 human antibodies for treating intractable diseases, including neurodegeneration. The authors are not 10 aware of any other affiliations, memberships, funding, or financial holdings that might be perceived as affecting the objectivity of this review.

Publisher's note: Springer Nature remains neutral with regard to jurisdictional claims in published maps and institutional affiliations.

Reviewer information

Nature Reviews Genetics thanks Emiliano Biasini, Claudio Soto and the other anonymous reviewer(s) for their contribution to the peer review of this work.

DISPLAY ITEMS

\section{Box 1 | Diagnosing prion diseases}

The transmissible nature of prion diseases (PrDs) and the resulting danger of contracting the disease iatrogenically make their correct diagnosis a pressing need for patients, their families and society. Historically, PrDs have been diagnosed based on their clinical symptoms and by excluding other diseases. Diagnosis is further supported by magnetic resonance imaging (MRI), electroencephalography (EEG), and the detection of surrogate markers in the cerebrospinal fluid (CSF). While diffusion patterns on MRI, periodic sharp and slow wave complexes on EEG and an upregulation of CSF markers such as 14-3-3 correlate with PrD, these assays usually simply indicate neuronal damage and even a combination of them is vastly insufficient for providing the sensitive and specific Page | 30 
1 results required ${ }^{182}$.

2 A definitive diagnosis of $\operatorname{PrD}$ requires the detection of protease-resistant prion deposits. However, prion

3 deposits are most prominent in the brain and their ante-mortem detection without a brain biopsy has proven to be a major challenge. Conventional immunoblotting and ELISA techniques are usually not sensitive enough to detect the minute amounts of prions in more accessible patient samples, such as blood. The detection of misfolded $\operatorname{PrP}$ is further complicated by the excess of normal $\operatorname{PrP}^{\mathrm{C}}$ in blood, and even the development of an ultrasensitive ELISA involving enrichment of aggregated PrP using steel powder only enabled the diagnosis of vCJD but not other types of $\operatorname{PrDs}^{183,184}$. Thus, the definitive diagnosis of PrD currently still depends on the analysis of brain samples, which, with a few exceptions involving brain biopsies, occurs postmortem. The presence of prion deposits can then be detected via immunoblotting or immunohistochemistry, and neuropathological changes such as gliosis, neuronal loss and spongiform changes can be visualized using immunohistochemistry.

Recently developed approaches have therefore concentrated on increasing the sensitivity of diagnostic tests by amplifying aggregates before detection. Protein misfolding cyclic amplification (PMCA) ${ }^{185}$, the amyloid seeding assay (ASA) ${ }^{186}$, and quaking-induced conversion (QuIC) $)^{187}$ have been applied to verify the presence of minute amounts of prions in infected specimen from animals and human. The further development of the real-time QUIC (RT-QUIC) assay allowed the assessment of human CSF samples ${ }^{188}$, and has now reached $96 \%$ sensitivity ${ }^{189}$ and $100 \%$ specificity ${ }^{188}$ in diagnosing CJD. Lately, the PMCA assay has been adapted for blood-based diagnosis of $\mathrm{vCJD}^{190,191}$; however, further studies are needed to validate this assay, especially regarding its application to other PrDs.

\section{Box 2 | Protein-misfolding disorders affecting the nervous system}

Neurodegenerative disorders have been linked to a variety of different protein aggregates and thus belong to the broader category of protein-misfolding disorders (PMDs). PMD-implicated proteins include APP, $\alpha$-synuclein, C9orf72, FUS, Huntingtin, Tau, TDP-43, and $\operatorname{PrP}^{\mathrm{C}}$. Triggers such as stress, age, or mutagenesis are thought to induce misfolding of these proteins into toxic oligomeric species ${ }^{142}$. Different diseases, even though sometimes caused by aggregates of the same protein, show a spectrum 
of neuropathological and clinical symptoms, indicating the presence of multiple aggregate strains that exert toxicity in distinct manners. With the exception of multiple system atrophy (MSA), which affects primarily oligodendrocytes, protein aggregates are usually most toxic to neurons. Synaptic defects seem to be an early event in neuronal PMDs and have been shown to cause neurodegeneration. Moreover, specific neuronal subtypes in different brain regions show a selective vulnerability to the different aggregates ${ }^{129,192,193}$. This suggests that the expression of co-factors such as receptors or chaperones can modulate the aggregate-induced toxicity and highlights the importance of cell-type specific future studies to decipher the differential vulnerability. The scheme below illustrates which protein aggregates cause which neuropathological (P) and clinical (C) changes and the associated PMD.

Figure 1 The nucleation and fragmentation cycle of prions and prionoids. Chaperones linked to protein synthesis (CLIPs) guide and oversee the correct folding of newly synthesized polypeptide chains $^{142}$. Misfolded proteins, induced by triggers such as overexpression, mutations, stress or age, either re-fold with the help of heat-shock proteins (HSPs), undergo degradation, or aggregate into $\beta$ sheet rich oligomers, which are considered the most toxic aggregate species. Endoplasmic reticulum associated protein degradation (ERAD) $)^{107,110}$ or HSP70-mediated ubiquitination target misfolded monomeric and oligomeric aggregates for proteasomal degradation. By contrast, HSP90 stabilizes oligomers $^{142}$, which can then form higher-order structures such as protofibrils or fibrils by incorporating correctly folded and misfolded monomeric proteins. The fragmentation of higher-order structures produces new propagons that can re-initiate the nucleation-fragmentation cycle.

\section{Figure 2 Structure of the prion protein and amino acid substitutions that have been linked to} genetic prion diseases.

a. Tertiary structure of the prion protein( PrP) deduced from an NMR structure ${ }^{21,194}$. The unstructured flexible tail (FT) at the N-terminus consists of two hydrophilic charge clusters, and the octapeptide repeat region. A hydrophic core links the FT with the globular domain at the C-terminus, encompassing three $\alpha$-helices, two short antiparallel $\beta$-sheets and two glycosylation sites. The addition of a glycosyl 
1 phosphoinositol modification at the $\mathrm{C}$-terminus anchors the protein to the plasma membrane.

2 b. Schematic representation of $\operatorname{PrP}$ and amino acid substitutions linked to the genetic prion diseases

3 Fatal Familial Insomnia (FFI), genetic Creutzfeldt-Jakob disease (gCJD) and Gerstmann-Straeussler-

4 Scheinker Syndrome (GSS). Where applicable, the amino acid present at polymorphic residue 129 is

5 indicated; ${ }^{33,195}$ : bold text indicates the presence of methionine; italic text indicates the presence of 6 valine; bold italic text indicates that the disease occurs irrespective of the amino acid residue at position

7 129. The asterisk indicates the substitution of an amino acid with a stop codon, which results in a

8 truncated version of the protein.

9

10 Figure 3 | Therapeutic approaches targeting protein aggregation.

11 Several different approaches have been undertaken to develop therapeutics for PMDs and show promising results in animal models. a. Overexpression of HSP70 and inhibition of HSP90 increases the degradation of misfolded proteins..

b. Anti-prions, innocuous versions of $\operatorname{Pr}^{\mathrm{Sc}}$, compete with the aggregates for the same substrate and result in the formation of novel innocuous aggregates .

c. Luminescent conjugated polythiophenes (LCPs) hyperstabilize aggregates, thereby interfering with the nucleation-fragmentation cycle and consequently reduce aggregate propagation.

d. Antibodies specifically recognize and bind aggregates and can lead to aggregate clearance via phagocytic cells, interfere with the aggregation process, or prevent aggregates from exerting toxicity. 


\section{Glossary}

\section{PRION DISEASES}

(PrDs) A group of diseases caused by an infectious protein, which includes genetic, acquired and sporadic forms .PrDs have an overall incidence of 1-2 cases per million individuals per year.

\section{PRION}

The agent causing transmissible spongiform encephalopathies (TSE). As originally defined, the term does not have structural implications other than that a protein is an essential component. Although it is now generally accepted that the prion consists largely of $\operatorname{PrP}^{\mathrm{Sc}}$, prions are defined as a biological activity rather than a physical entity. Hence they can be measured by activity assays rather than by quantitating $\operatorname{PrP}^{\mathrm{Sc}}$.

\section{AgGRegates}

In the context of this review, the term "aggregate" is used to denote the coalescence of misfolded proteins into highly ordered structures, typically resulting in the formation of fibrils.

\section{PROTEIN MISFOLDING DISORDERS}

(PMDs) Disorders that are characterized by protein aggregates, which induce neurodegeneration if present in the brain.

\section{PROPAGON}

The minimal propagating unit of a misfolded protein, defined by its capacity to self-replicate in vitro and/or in vivo. A propagon that can transmit from a host individual to another individual is called a prion.

\section{PRIONOIDS}

Protein aggregates that can propagate and spread between cells, but for which transmissibility between individuals has not yet been demonstrated.

\section{POLYMORPHISMS}

Any sites in the DNA sequence that are present in the population in more than one state.

\section{Penetrance}

the percentage of individuals with a mutation that exhibit clinical symptoms. Most $P R N P$ mutations are highly penetrant, meaning that most individuals with PRNP mutations develop PrD.

\section{PRION STRAINS}

Entities associated with distinct biochemical and neuropathological profiles, translating into a spectrum of incubation periods and clinical signs. Crucially, strain-specific traits are stable across serial transmission among isogenic hosts, indicating that they are encoded by the prion itself. Distinct structural assemblies of chemically identical $\mathrm{PrP}^{\mathrm{Sc}}$ are thought to underlie strainness.

\section{PhASE DEMIXING}

Process of membraneless compartmentalization. Spontaneous demixing of two coexisting phases is driven by inter-molecular interactions, a propensity that seems to be particularly high for proteins with low-complexity domains.

\section{ЕХСІтотоХICITY}

Neuronal overstimulation caused by increased levels of the excitatory neurotransmitter glutamate leading to calcium overload and mitochondrial dysfunction, and ultimately to neuronal cell death and memory loss.

\section{PARABIOSIS}

Surgical technique to anatomically connect two indivuals. The shared circulatory system between the individuals allows specific factors to be assessed for their involvement in regulating physiological functions, behavior, and disease pathogenesis. 
2 ONLINE ONLY

\section{Subject categories}

4 Biological sciences / Molecular biology / Protein folding / Prions [URI /631/337/470/460]

5 Health sciences / Neurology / Neurological disorders / Prion diseases [URI /692/617/375/1937]

6 Health sciences / Diseases / Neurological disorders / Neurodegenerative diseases [URI

7 1692/699/375/365]

8 Biological sciences / Neuroscience / Diseases of the nervous system / Neurodegeneration [URI

9 /631/378/1689/364]

10 Biological sciences / Molecular biology / Protein folding / Protein aggregation [URI

$11 / 631 / 337 / 470 / 2284]$

13 ToC blurb

14 Parallels are increasingly being drawn between prion diseases and other aggregate-mediated 15 neurodegenerative disorders. While prion diseases are a distinct subclass of protein misfolding disorders 16 (PMDs), a better understanding of shared mechanisms is likely to benefit treatment of all PMDs. 